\title{
ENRAIZAMENTO DE ESPÉCIES SILVESTRES DE MARACUJAZEIRO UTILIZANDO CINCO DOSES DE ÁCIDO INDOLILBUTÍRICO ${ }^{1}$
}

\author{
CAROLINA DE FARIA VAZ ${ }^{2}$, JOSÉ RICARDO PEIXOTO³,NILTON TADEU VILELA JUNQUEIRA ${ }^{4}$, \\ MARCELO FIDELES BRAGA ${ }^{4}$, ERIVANDA CARVALHO DOS SANTOS 5 , \\ KENIA GRACIELE DA FONSECA ${ }^{6}$, KEIZE PEREIRA JUNQUEIRA ${ }^{7}$
}

RESUMO - Este trabalho teve como objetivo avaliar em casa de vegetação o potencial de enraizamento de diferentes espécies silvestres de maracujá, utilizando diferentes doses de ácido indolilbutírico. Estacas herbáceas de plantas adultas de Passiflora setacea, P. coccinea, P. amethystina, P. edulis, P. edulis x P. setacea e $P$. coccinea $\times$ P. setacea foram coletadas e tratadas com doses de $0 ; 250 ; 500 ; 750$ e $1.000 \mathrm{mgL}^{-1}$ de IBA, sendo em seguida plantadas em bandejas com substrato umedecido e mantidas sob nebulização intermitente. $\mathrm{O}$ delineamento experimental adotado foi o de blocos ao acaso, com 5 repetições, em arranjo fatorial de $6 \mathrm{x}$ 5 (seis espécies e cinco níveis de regulador vegetal) e 6 estacas úteis por unidade experimental. As variáveis analisadas foram estaca viva com raiz e com broto (EVCRCB), estaca viva com raiz e sem broto (EVCRSB), estaca viva com calo (EVCC), estaca viva sem calo (EVSC), total de estacas enraizadas (TER), estaca morta com raiz (EMCR), estaca morta com calo (EMCC), estaca morta sem calo (EMSC), total de estaca morta (TEM), estaca com broto (ECB), média de estacas com broto (MEB), massa seca da raiz (MSRA), massa seca do broto (MSBRO) e massa seca total (MSTOTAL). A espécie P. amethystina apresentou o melhor desenvolvimento, destacando-se entre as outras espécies e mostrando potencial para enraizamento, tendo $88,67 \%$ de estacas enraizadas e brotadas. O uso do IBA foi eficiente à medida que se aumentavam as doses, proporcionando bom desenvolvimento às estacas das espécies estudadas.

Termos para indexação: Passiflora spp., propagação, produção de mudas, estaquia, regulador vegetal.

\section{ROOTING OF WILD SPECIES OF PASSION FRUIT USING FIVE DOSES OF INDOLEBUTYRIC ACICID}

\begin{abstract}
The aim of this work was to evaluate under greenhouse conditions, the rooting potential of different wild species of passion fruit using different doses of indolebutyric acid. Herbaceous cuttings of adult plants of Passiflora setacea, P. coccinea, P. amethystina, P. edulis, P. edulis x P. setacea and P. coccinea $\times$ P. setacea were collected and treated with doses of 0, 250, 500, 750 and $1000 \mathrm{mgL}^{-1}$ of IBA, and then planted in trays with moistened substrate and held under intermittent mist. The experimental design was in randomized blocks with 5 replications and $6 \times 5$ factorial arrangement (six species and five IBA levels) and 6 useful cuttings per experimental unit. The variables observed were rooted living cutting with sprouts (RLCWS), rooted living cutting without sprouts (RLCWOS), living cutting with callus (LCWC), living cutting without callus (LCWOC), total of rooted cuttings (TRC), dead rooted cutting (DRC), dead cutting with callus (DCWC), dead cutting without callus (DCWOC), total of dead cuttings (TDC), cutting with sprouds (CWS), average cuttings with sprouts (ACWS), root dry matter (ROOTDM), sprout dry matter (SPRDM), and total of dry matter (TOTALDM). The P. amethystina species presented better development than other species, showing rooting potential, with $88.67 \%$ of cuttings with roots and sprouts. The use of IBA was efficient as the doses were increased, providing a good development for cuttings of the studied species. Index terms: Passiflora sp., vegetative propagation, production of seedlings, cuttings, plant growth regulators.
\end{abstract}

\footnotetext{
${ }^{1}$ (Trabalho 144-08). Recebido em: 09-06-2008. Aceito para publicação em: 23-06-2009.Parte da Dissertação de Mestrado.

${ }^{2}$ Mestre em Produção Vegetal, Ciências Agrárias/Universidade de Brasília, Câmpus Universitário Darcy Ribeiro, 70910-900. BrasíliaDF. Estagiária da Embrapa Cerrados BR 020 Km 18, C.P. 08223, 73010-970 Planaltina - DF. Email: carolfariav@yahoo.com.br. ${ }^{3}$ Prof. da Universidade de Brasília, Câmpus Darcy Ribeiro, C. P. 04508, Universidade de Brasília, CEP 70910-900, Brasília - DF Email: peixoto@unb.br

${ }^{4}$ Pesquisador da Embrapa Cerrados, BR 020 Km 18, C. P. 08223, 73010-970 Planaltina- DF. Email: junqueira@cpac.embrapa.br; fideles@cpac.embrapa.br

${ }^{5}$ Bolsista da Embrapa Cerrados BR 020 Km 18, C.P. 08223, 73010-970 Planaltina - DF. Email: erivanda@cpac.embrapa.br ${ }^{6}$ Mestre em Produção Vegetal, Ciências Agrárias/Universidade de Brasília, Câmpus Universitário Darcy Ribeiro, 70910-900. BrasíliaDF. Estagiária da Embrapa Cerrados BR 020 Km 18, C.P. 08223, 73010-970 Planaltina - DF. Email: keniagro@yahoo.com.br ${ }^{7}$ Doutoranda do Curso de Fitopatologia/Universidade de Brasília, Câmpus Universitário Darcy Ribeiro, 70910-900 Brasília-DF. Email: keizejunqueira@hotmail.com
} 


\section{INTRODUÇÃO}

A estaquia é uma das técnicas de propagação vegetativa do maracujazeiro que permite a obtenção de pomares uniformes. É um dos principais métodos utilizados na multiplicação de plantas frutíferas (Fachinello et al., 2005). Em trabalho realizado por Junqueira et al. (2006), no qual se avaliaram a reação a doenças e a produtividade de maracujazeiro-azedo propagado por estaquia e enxertia, os autores concluíram que plantas propagadas por estaquia produzem frutos com maior massa fresca e em maior número, quando comparadas às plantas propagadas por sementes e enxertia, ou seja, em termos de produtividade, as plantas propagadas por estaquia produziram o dobro das demais. A maior produtividade dessas plantas propagadas por estaquia pode ser explicada pelo efeito da seleção clonal ou pela maior resistência às doenças.

No Brasil, em algumas regiões, o cultivo comercial de maracujá-amarelo enfrenta problemas com patógenos de solo, que têm causado sérios prejuízos e até mesmo inviabilizado a cultura em determinadas áreas. Uma solução a curto prazo seria o uso de mudas enxertadas através de estacas enraizadas de passifloras nativas. Em algumas espécies silvestres de maracujá, existe alta variabilidade em relação à resistência, suscetibilidade e tolerância a doenças (Hartmann et al., 1997). Conforme relatados por Menezes et al. (1994), Oliveira et al. (2000) e Fisher et al. (2003), várias espécies de Passiflora possuem resistência aos principais patógenos do solo, como: Passiflora alata, Passiflora caerulea L., Passiflora giberti N. E, Br., Passiflora macrocarpa Linden, Passiflora nitida Kunth, Passiflora quadrangularis e Passiflora setacea, e estas devem ser utilizadas no processo de enxertia.

Um fator limitante para o uso das espécies silvestres de Passiflora seria o diâmetro do caule das plântulas obtidas por sementes, dificultando a operação de enxertia. Segundo Chaves et al. (2004), a enxertia em estacas enraizadas seria a solução, pois, além de apresentarem diâmetro maior que as plântulas, as estacas apresentam a vantagem da clonagem, conferindo mais uniformidade às mudas obtidas.

O objetivo deste trabalho foi avaliar o enraizamento de estacas de espécies silvestres e híbridos interespecíficos de maracujazeiros utilizando diferentes doses de IBA (ácido indolilbutírico).

\section{MATERIAL E MÉTODOS}

O experimento foi desenvolvido na Embrapa Cerrados, em Planaltina-DF (latitude $15^{\circ} 35^{\prime} 00^{\prime \prime}$, longitude $47^{\circ} 35^{\prime} 00^{\prime}$ "e altitude de $1050 \mathrm{~m}$ ), em casa de vegetação, com temperatura de $18 \pm 2^{\circ} \mathrm{C}$ à noite e $25 \pm 2^{\circ} \mathrm{C}$ ao dia e umidade relativa de 70 a $100 \%$ equipada com sistema de nebulização intermitente acionada por umidostato. $\mathrm{O}$ delineamento experimental foi o de blocos ao acaso, com 5 blocos, 30 tratamentos em arranjo fatorial $6 \times 5$ (seis espécies e cinco níveis de ácido indolilbutírico - IBA) e 6 estacas úteis por unidade experimental. Estacas herbáceas de Passiflora edulis (gigante amarelo), Passiflora setacea (CPAC MJ 12-01), Passiflora coccinea (CPAC MJ 08-20), Passiflora amethystina (CPAC MJ 13-01), um híbrido F1 proveniente do cruzamento de $P$. coccinea $x$ P setacea e outro híbrido proveniente do cruzamento de $P$. edulis $x P$. setacea foram coletadas junto à coleção de passifloras da Embrapa Cerrados. As estacas foram retiradas da parte mediana dos ramos, com comprimento de 40 $\mathrm{cm}$ e transportadas em sacos plásticos para a casa de vegetação, onde foram preparadas, deixando-se duas folhas nos nós superiores. Foi feito um corte em bisel na base da estaca, expondo o câmbio vascular objetivando um maior enraizamento.

Após o corte na base da estaca, estas tiveram suas bases imersas aproximadamente $10 \mathrm{~cm}$ durante um minuto em solução com ácido indolilbutírico (IBA), nas concentrações de $0 ; 250 ; 500 ; 750$ e $1.000 \mathrm{mgL}^{-1}$.

As estacas foram plantadas em substrato organomineral de vermiculita (Plantmax ${ }^{\circledR}$ Hortaliças) em bandejas de poliestireno com 72 células, cada célula com $12 \mathrm{~cm}$ de profundidade.

Ao final dos 90 dias, avaliaram-se o número de estacas vivas com raiz, o número de estacas vivas com calo, o número de estacas vivas sem calo, as estacas mortas com raiz, estacas mortas com calo e mortas sem calo, o número de estacas com brotação e o número de brotos. Durante a avaliação, para evitar danos ao sistema radicular e melhor visualização do seu desenvolvimento, o substrato de cada estaca foi retirado por lavagem com jato de água moderado. As raízes foram retiradas das estacas e acondicionadas em sacos de papel, um saco para cada estaca, sendo identificados conforme a parcela e o tratamento, e colocados em estufa de bancada para secar a $75^{\circ} \mathrm{C}$, permanecendo por 72 horas (BRAGA et al., 2006). Após três dias, as raízes e os brotos foram pesados e então descartados.

As análises estatísticas do experimento 
constam da análise de variância, teste de Tukey para comparação das médias das espécies e regressão polinominal para os níveis da auxina, ao nível de significância de 5\%. As variáveis analisadas foram transformadas antes da análise de variância, segundo $\sqrt{x+1}$ e arco/seno.

\section{RESULTADOS E DISCUSSÃO}

Estacas enraizadas e com presença de brotos indicam o fechamento do ciclo de formação da muda, sendo esta a resposta de maior interesse. Verifica-se que a espécie $P$. amethystina se destaca entre as demais, apresentando maior índice de estacas enraizadas e brotadas $(88,7 \%)$, bem como para a variável total de estacas enraizadas $(90,7 \%)$, evidenciando que esta espécie apresenta potencial para enraizamento (Tabela 1). Observando o comportamento desta espécie em relação à emissão de brotos, $P$. amethystina apresentou 5,3\% de estacas brotadas em uma parcela experimental com 6 estacas úteis (Tabela 2). Esta espécie também se destacou quanto ao número de brotos por parcela (NBPAR) e média de brotos por estaca (BEM), evidenciando mais uma vez o seu elevado potencial para enraizamento e emissão de brotos (Tabela 2). Paula (2006), trabalhando com espécies silvestres de Passiflora relata que, quando tratadas com IBA a $2.000 \mathrm{mgL}^{-1}$, estacas de $P$. amethystina apresentaram $93 \%$ de enraizamento, $P$. coccínea (47,13\%), P. setacea (46,7\%) e o híbrido P.coccinea x P.setacea (42,21\%). Pode-se dizer que os resultados encontrados pelo autor acima foram inferiores aos resultados deste experimento, onde a espécie $P$. coccinea apresentou 75,34\%, P. setacea $73,34 \%$ e o híbrido de $P$. coccinea $\times$ P. setacea $76 \%$ de enraizamento.

Apesar de os acessos das espécies estudadas terem sido os mesmos para os dois experimentos, pode-se dizer que o que teria influenciado na diferença dos resultados seria a dosagem de IBA, às condições climáticas diferenciadas e possíveis problemas fitossanitários e ambientais. Roncatto et al. (2003), observando algumas espécies de passifloras, concluíram que a sobrevivência, o número e o comprimento de raízes foram maiores na primavera. Portanto, a condição da matriz, seja em relação à época de retirada das estacas, seja em relação à predisposição genética, pode ser fator importante.

A espécie $P$. setacea apresentou bom desenvolvimento,com baixos índices de mortalidade. Apesar do significativo índice de enraizamento, esta espécie diferenciou-se das demais em relação às variáveis EVCC (estaca viva com calo) e EVSC (estaca viva sem calo) $(9,3 \%$ e $4 \%$, respectivamente), necessitando de um período maior para fechar o ciclo de formação da muda (Tabela 1). Apesar de ter havido efeito significativo em relação às duas variáveis citadas acima, estes valores são irrelevantes perante o total de estacas enraizadas (73,34\%).

Além da presença de raízes, o volume formado é um fator importante na avaliação da qualidade do enraizamento. $P$. amethystina apresentou o maior valor para massa seca de raiz $(6,62 \mathrm{~g}) \mathrm{em}$ comparação com as outras espécies, porém, em relação à massa seca de broto (MSBRO), esta espécie apresentou baixo valor $(8,61 \mathrm{~g})$, não diferindo significativamente de $P$. setacea, que apresentou o menor valor para esta variável $(7,81 \mathrm{~g})$. Observando a massa total da matéria seca (MSTOTAL), característica que expressa o potencial do regulador vegetal, $P$. edulis difere significativamente das outras, mostrando-se eficiente na produção de matéria seca da parte aérea e de raízes (Tabela 3 ).

Em relação ao total de estacas mortas (TEM), P. setacea apresentou baixo valor (13\%), aproximando-se de $P$. amethystina $(8,7 \%)$ e $P$. edulis $(12 \%)$, que apresentaram os menores valores (Tabela 4). O híbrido I ( $P$. edulis x P. setacea) destacou-se entre as espécies avaliadas, com valor de $32 \%$. Os dados obtidos neste experimento mostram que esse híbrido, além de apresentar os maiores índices de mortalidade, também apresentou baixo percentual de estacas enraizadas e brotadas, como observado nas variáveis: total de estacas enraizadas (TER) e total de estacas mortas (TEM) (Tabelas 1 e 4). Junqueira et al. (2001) relatam que o ataque do díptero Bradysia sp. causa perdas expressivas em plantios de estacas, pois a praga deposita os ovos poucos dias após o plantio das estacas, ou seja, momento bem anterior ao tratamento químico. Outro fator que, provavelmente, favoreceu a mortalidade das estacas, foi a presença de fungos através da elevada umidade sob a qual as estacas foram mantidas no experimento.

Não foi observado efeito significativo na interação Espécie x IBA em nenhum dos parâmetros avaliados. Através da regressão polinominal, verificou-se que o uso do regulador vegetal influenciou no enraizamento de estacas e nas características de crescimento dos brotos (Figuras 1; 2; 3; 4 e 5), apresentado ajuste linear em todas as características avaliadas. Conforme as equações lineares, com um aumento de $250 \mathrm{mgL}^{-1}$ do regulador vegetal (IBA), espera-se aumento médio de 0,0521 no número de estacas com raiz e brotos (EVCRCB), 0,0481 no número de estacas com brotos (ECB), 0,08705 no número de brotos por parcela (NBPAR), 0,0087 na massa seca de raiz (MSRA) e 0,026 na massa seca total (MS Total). Portanto, não foi 
possível determinar a dose ideal do regulador vegetal (IBA) para o enraizamento de estacas das espécies de maracujazeiro avaliadas; no entanto, pôde-se verificar que doses crescentes de IBA proporcionaram os melhores resultados.

TABELA 1 - Estaca viva com raiz e com broto (EVCRCB). Estaca viva com raiz e sem broto (EVCRSB), total de estacas enraizadas (TER), estacas vivas com calo (EVCC) e estacas vivas sem calo (EVSC) de quatro espécies e dois híbridos de maracujazeiro tratados com diferentes níveis do ácido indolilbutírico (IBA). Brasília - DF, Embrapa Cerrados, 2008.

\begin{tabular}{|c|c|c|c|c|c|c|c|c|c|c|c|c|}
\hline Espécies & P.setace & & P.coccil & & P.amethy & tina & P.edulis & & Híbrido & & Híbrido & \\
\hline Variáveis & Média & $*$ & Média & * & Média & $*$ & Média & $*$ & Média & $*$ & Média & $*$ \\
\hline EVCRCB (\%) & 60,67 & $\mathrm{~b}$ & 68,67 & al & 88,67 & $\mathrm{a}$ & 81,33 & $a b$ & 66,00 & $\mathrm{~b}$ & 70,00 & $a b$ \\
\hline EVCRSB (\%) & 12,67 & $\mathrm{a}$ & 6,67 & $\mathrm{a}$ & 2,00 & $\mathrm{~b}$ & 67 & $a b$ & 0,67 & $\mathrm{~b}$ & 6,00 & $a b$ \\
\hline TER(\%) & 73,34 & $a b$ & 75,34 & $a b$ & 90,67 & $\mathrm{a}$ & 88,00 & $\mathrm{a}$ & 66,67 & $\mathrm{D}$ & 76,00 & $a b$ \\
\hline $\operatorname{EVCC}(\%)$ & 9,33 & $\mathrm{a}$ & 0,00 & $\mathrm{~b}$ & 0,67 & $\mathrm{~b}$ & 0,00 & $\mathrm{~b}$ & 0,67 & $\mathrm{~b}$ & 1,33 & $\mathrm{~b}$ \\
\hline EVSC (\%) & 4,00 & $\mathrm{a}$ & 0,00 & b & 0,00 & $\mathrm{~b}$ & 0,00 & $\mathrm{~b}$ & 0,67 & $a b$ & 0,67 & $a b$ \\
\hline
\end{tabular}

Médias com letras diferentes, na mesma linha, diferem estatisticamente entre si, pelo teste de Tukey, a 5\% de probabilidade. Híbrido I - P. edulis x P. setacea Híbrido II - P. coccinea x $P$. setacea

TABELA 2 - Média de brotos por estaca (MEB), estaca com broto (ECB) e número de estacas por parcela (NBPAR) de quatro espécies e dois híbridos de maracujazeiro tratados com diferentes níveis do ácido indolilbutírico (IBA). Brasília - DF, Embrapa Cerrados, 2008.

\begin{tabular}{lcccccccccccccc}
\hline Espécies & \multicolumn{2}{c}{ P.setacea } & \multicolumn{3}{c}{ P.coccinea } & \multicolumn{3}{c}{ P.amethystina } & P.edulis & \multicolumn{3}{c}{ Híbrido I } & \multicolumn{2}{c}{ Híbrido II } \\
Variáveis & Média & $*$ & Média & $*$ & Média & $*$ & Média & $*$ & Média & $*$ & Média & $*$ \\
\hline BEM & 1,54 & $\mathrm{c}$ & 1,60 & $\mathrm{c}$ & 2,72 & $\mathrm{a}$ & 1,69 & $\mathrm{bc}$ & 2,08 & $\mathrm{~b}$ & 1,74 & $\mathrm{bc}$ \\
ECB & 4,12 & $\mathrm{ab}$ & 4,12 & $\mathrm{~b}$ & 5,32 & $\mathrm{a}$ & 4,88 & $\mathrm{ab}$ & 4,08 & $\mathrm{~b}$ & 4,36 & $\mathrm{ab}$ \\
NBPAR & 6,40 & $\mathrm{~b}$ & 6,56 & $\mathrm{~b}$ & 14,52 & $\mathrm{a}$ & 8,28 & $\mathrm{~b}$ & 8,6 & $\mathrm{~b}$ & 7,44 & $\mathrm{~b}$ \\
\hline
\end{tabular}

Médias com letras diferentes, na mesma linha, diferem estatisticamente entre si, pelo teste de Tukey, a 5\% de probabilidade. Híbrido I - P. edulis x P. setacea híbrido II - P. coccinea $\times$ P. setacea

TABELA 3 - Massa seca de raiz (MSRA), massa seca do broto (MSBRO) e massa seca total (MS Total) de estacas de quatro espécies e dois híbridos de maracujazeiro tratados com diferentes níveis do ácido indolilbutírico (IBA). Brasília - DF, Embrapa Cerrados, 2008.

\begin{tabular}{|c|c|c|c|c|c|c|c|c|c|c|c|c|}
\hline Espécies & \multicolumn{2}{|l|}{ P.setacea } & \multicolumn{2}{|c|}{ P.coccinea } & \multicolumn{2}{|c|}{ P.amethystina } & \multicolumn{2}{|l|}{ P.edulis } & \multicolumn{2}{|c|}{ Híbrido I } & \multicolumn{2}{|c|}{ Híbrido II } \\
\hline Variáveis & Média & $*$ & Média & $*$ & Média & $*$ & Média & $*$ & Média & * & Média & * \\
\hline MSRA (g) & 2,8 & $\mathrm{c}$ & 5,64 & $\mathrm{ab}$ & 6,62 & a & 6,23 & $a b$ & 4,36 & bc & 5,04 & $a b$ \\
\hline MSBRO (g) & 7,81 & $\mathrm{c}$ & 13,60 & bc & 8,61 & $\mathrm{c}$ & 26,59 & $\mathrm{a}$ & 21,21 & $a b$ & 20,87 & $a b$ \\
\hline MSTOTAL (g) & 10,61 & d & 19,24 & bc & 15,23 & bd & 32,82 & $\mathrm{a}$ & 25,57 & $a b$ & 25,91 & $a b$ \\
\hline
\end{tabular}

Médias com letras diferentes, na mesma linha, diferem estatisticamente entre si, pelo teste de Tukey, a 5\% de probabilidade. Híbrido I - P. edulis x P. setacea híbrido II - P. coccinea $\mathrm{x}$ P. setacea 
TABELA 4 - Estaca morta com raiz (EMCR), estaca morta com calo (EMCC), estaca morta sem calo (EMSC) e total de estacas mortas (TEM) de quatro espécies e dois híbridos de maracujazeiro tratados com diferentes níveis do ácido indolilbutírico (IBA). Brasília - DF, Embrapa Cerrados, 2008.

\begin{tabular}{lcccccccccccccc}
\hline Espécies & \multicolumn{2}{c}{ P.setacea } & \multicolumn{3}{c}{ P.coccinea } & \multicolumn{3}{c}{ P.amethystina } & P.edulis & \multicolumn{3}{c}{ Híbrido I } & \multicolumn{3}{c}{ Híbrido II } \\
Variáveis & Média & $*$ & Média & $*$ & Média & $*$ & Média & $*$ & Média & $*$ & Média & $*$ \\
\hline EMCR (\%) & 1,33 & a & 4,67 & a & 0,0 & a & 0,67 & a & 2,00 & a & 0,67 & a \\
EMCC (\%) & 2,67 & a & 0,67 & a & 0,0 & a & 0,00 & a & 2,00 & a & 0,67 & a \\
EMSC (\%) & 9,33 & b & 19,33 & ab & 8,7 & b & 11,33 & b & 28,00 & a & 20,67 & ab \\
TEM (\%) & 13,33 & b & 24,67 & ab & 8,7 & b & 12,00 & b & 32,00 & a & 22,01 & ab
\end{tabular}

Médias com letras diferentes, na mesma linha, diferem estatisticamente entre si, pelo teste de Tukey, a $5 \%$ de probabilidade. Híbrido I-P. edulis $\mathrm{x} P$. setacea híbrido II - P. coccinea $\mathrm{x}$ P. setacea

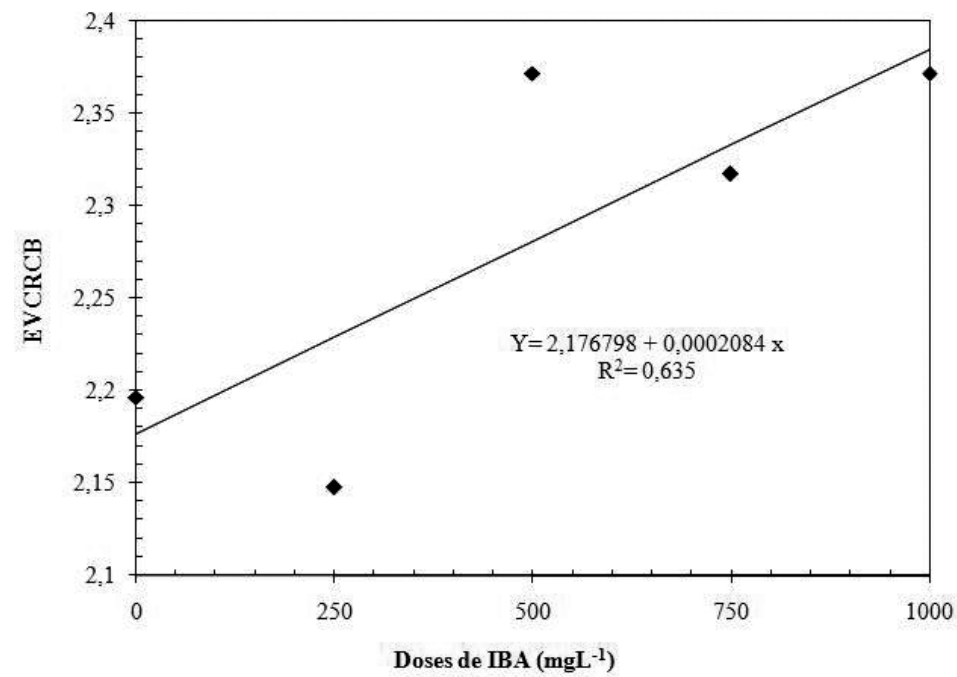

FIGURA 1 - Número de estacas com raiz e com broto (NVCRCB) de Passiflora spp. tratadas com ácido indolilbutírico (IBA). Brasília - DF, Embrapa Cerrados, 2008.

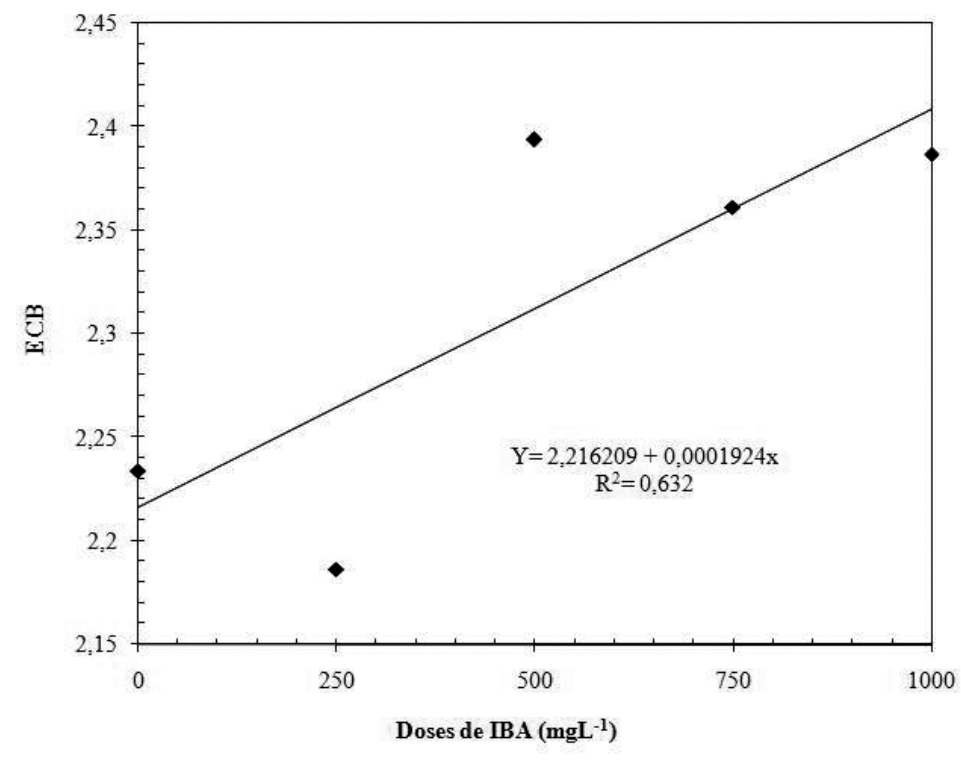

FIGURA 2 - Número de estacas com broto (ECB) de Passiflora spp tratadas com ácido indolilbutírico (IBA). Brasília - DF, Embrapa Cerrados, 2008. 


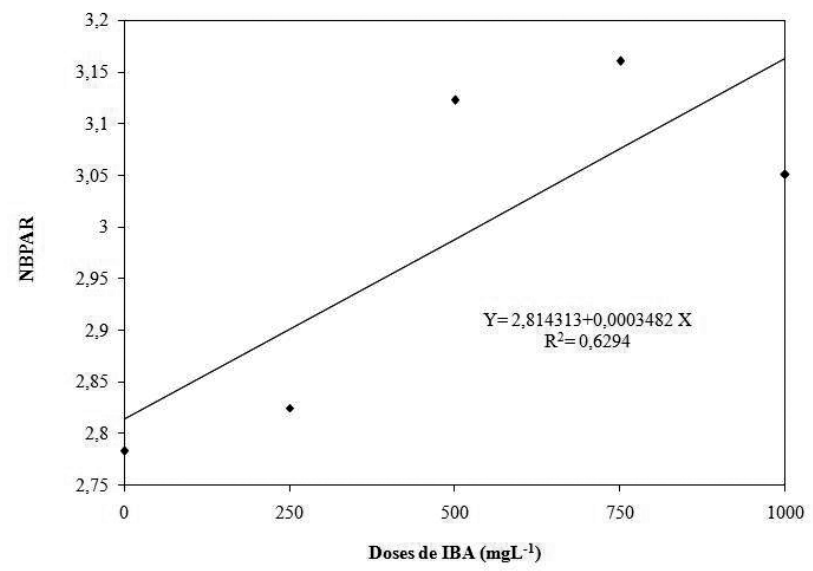

FIGURA 3 - Número de brotos por parcela (NBPAR) de estacas de Passiflora spp. tratadas com ácido indolilbutírico (IBA). Brasília - DF, Embrapa Cerrados, 2008.

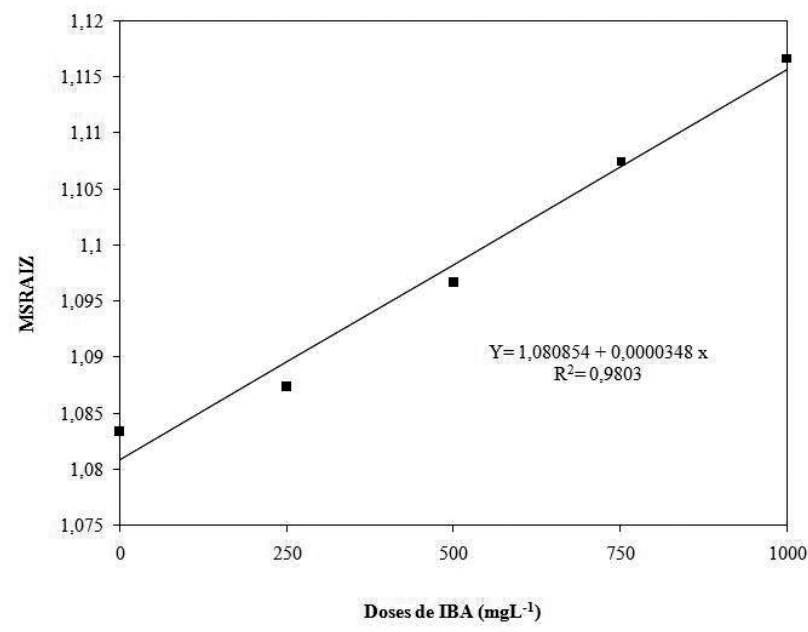

FIGURA 4 - Massa seca de raízes (MSRA) de estacas de Passiflora spp. tratadas com ácido indolilbutírico (IBA). Brasília - DF, Embrapa Cerrados, 2008.

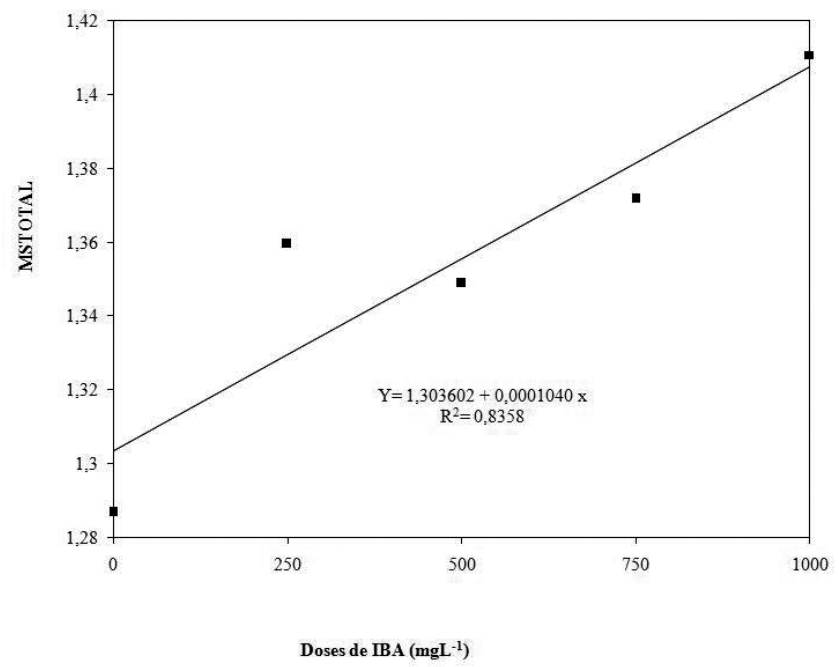

FIGURA 5 - Massa seca total (MS Total) de estacas de Passiflora spp. tratadas com ácido indolilbutírico (IBA). Brasília - DF, Embrapa Cerrados, 2008. 


\section{CONCLUSÕES}

A espécie Passiflora amethystina (CPAC MJ 13-01) apresentou maior potencial no enraizamento e na formação de mudas.

1-A alta taxa de mortalidade das estacas foi o principal fator limitante ao enraizamento de P. edulis $x$ P. setacea.

2-A espécie P. setacea (CPAC MJ 12-01) apresentou resposta lenta ao enraizamento, quando comparada às outras espécies.

3-À medida que se aumentou a dose de IBA, aumentou-se também o número de estacas enraizadas e brotadas (EVCRCB), o número de estacas com broto (ECB), o número de brotos por parcela (NBPAR), a massa seca de raiz (MSRA) e a massa seca total (MS TOTAL).

\section{REFERÊNCIAS}

BRAGA, M. F.; SANTOS, E. C.; JUNQUEIRA, N. T. V.; SAUSA, A. A. T. C.; FALEIRO, F. G.; REZENDE, L. N.; JUNQUEIRA, K. P. Enraizamento de três espécies silvestres de Passiflora. Revista Brasileira de Fruticultura, Jaboticabal, v. 28, n. 2, p. $284-288,2006$.

CHAVES, R. C.; JUNQUEIRA, N. T. V.; MANICA, I.; PEIXOTO, J. R.; PEREIRA, A. V.; FIALHO, J. F. Enxertia de maracujazeiro-azedo em estacas herbáceas enraizadas de espécies de passifloras nativas. Revista Brasileira de Fruticultura, Jaboticabal, v. 26, n. 1, p. 120-123, 2004.

FACHINELLO, J. C.; HOFFMANN, A.; NACHTIGAL, J. C.; KERSTEN, E. Propagação vegetativa por estaquia. In: FACHINELLO, J.; HOFFMANN, A.; NACHTIGA, J.C. (Eds.). Propagação de plantas frutíferas. Brasília: Embrapa Informação Tecnológica, 2005. 221p.

FISCHER, I. H. Seleção de plantas resistentes e de fungicidas para o controle da "Morte Prematura" do maracujazeiro, causada por Nectria haematococca e Phytophathora parasítica. 2003. 60 f. Dissertação (Mestrado) - Escola Superior de Agricultura “Luiz de Queiroz”, Universidade de São Paulo, Piracicaba, 2003.
HARTMANN, H. T.; KESTER, D. E.; DAVIES JR, F. T.; GENEVE, R. L. Plant propagation: principles and practices. 6. ed. New Jersey: Prentice Hall, 1997. p. 276-316.

JUNQUEIRA, N. T. V.; LAGE, D. A.; BRAGA, M. F.; PEIXOTO, J. R.; BORGES, T. A.; ANDRADE, S. R. M. de. Reação a doenças e produtividade de um clone de maracujazeiro-azedo propagado por estaquia e enxertia em estacas herbáceas de Passiflora silvestre. Revista Brasileira de Fruticultura, Jaboticabal, v.28, n. 1, p. 97 - 100, 2006.

JUNQUEIRA, N.T.V.; MANICA, I.; CHAVES, R. C.; LACERDA, C.S.; OLIVEIRA, J. A.; FIALHO, J. F. Produção de mudas de maracujazeiro-azedo por estaquia em bandejas. Planaltina: Embrapa Cerrados, 2001. (Recomendações Técnicas, 42)

MENEZES, J. M. T.; OLIVEIRA, J. C. de; RUGGIERO, C.; BANZATTO, D. A. Avaliação da taxa de pegamento sobre espécies tolerantes à morte prematura de plantas. Científica, Jaboticabal, v. 22, n. 1, p. 95-104, 1994.

OLIVEIRA, J. A. Efeito dos substratos artificiais no enraizamento e no desenvolvimento de maracujá-azedo e doce por estaquia. $2000.71 \mathrm{f}$. Dissertação (Mestrado em Agronomia) - Faculdade de Agronomia e Medicina Veterinária, Universidade de Brasília, Brasília, 2000.

PAULA, M. S.; PEIXOTO, J. R.; FALEIRO, F. G.; BELLON, G.; JUNQUEIRA, K. P.; BRAGA, M. F.; JUNQUEIRA, N. T. V. Informações preliminares sobre enraizamento de estacas de espécies silvestres e comerciais de Passiflora. In: REUNIÃO TÉCNICA DE PESQUISAS EM MARACUJAZEIRO, 4., 2005, Planaltina. Anais... Planaltina: Embrapa Cerrados, 2006. p. 96-99.

RONCATTO, G.; NOGUEIRA FILHO, G. C.; RUGGIERO, C.; OLIVEIRA, J. C.; MARTINS, A. B. G. Avaliação do comportamento de diferentes espécies de maracujazeiro (Passiflora spp.) propagadas por estaquia. In: CONGRESSO BRASILEIRO DE FRUTICULTURA, 17., 2002, Belém. Anais... Jaboticabal: Sociedade Brasileira de Fruticultura, 2002. CD-ROM. 